\title{
ACERCA DAS IDENTIDADES E SITUAÇÕES: PENSAMENTOS SOBRE A EMANCIPAÇÃO ${ }^{1}$
}

\author{
Maria Beatriz Greco ${ }^{2}$ \\ Facultad de Psicología. Universidad de Buenos Aires. \\ Facultad de Derecho. Argentina
}

El presente trabajo recorre los caminos de la constitución de la subjetividad preguntándose por los sujetos y sus identidades. Se plantea que la identidad sólo es tal desde otro, retomando diversas perspectivas teóricas: los enfoques situacionales, el psicoanálisis, la filosofía política. Los conceptos de el lazo social, situación, proyecto identificatorio, prestación de identidad y deuda de vida que es deuda debida, ley simbólica y palabra que nombra al sujeto que la busca mientras la hace propia, hablan -en lenguas diversas- acerca de los sinuosos caminos de la emancipación en los que los seres humanos nos hacemos a nosotros mismos con otros, a partir de otros, unidos y separados de los otros. El trabajo en ese espacio intermedio entre-sujetos, en las instituciones donde la transmisión se despliega, demanda una y otra vez reavivar las preguntas, no tanto por quiénes son ellos y ellas: "los nuevos", sino por el papel de los adultos en relación a estos "recién llegados”, lugares de padres, madres, maestros, autoridades, postas parentales, pasadores de cultura, referentes, anfitriones... y obliga a reformular la tarea irrenunciable de la transmisión. Finalmente, el trabajo propone pensar los procesos emancipatorios y su articulación en la transmisión a partir de la figura del maestro ignorante, propuesta por Rancière, la que habilita a reflexionar acerca del lugar de la autoridad en educación y la ley simbólica que encarna.

Descriptores: Identidad. Interacción simbólica. Influencias sociales. Educación.

1 Este trabalho inclui o conteúdo da tese de mestrado intitulada "Crítica ao conceito de autoridade em Rancière”, apresentada, em 2005, no Departamento de Filosofia da Universidade Paris 8.

2 Endereço para correspondência: Heredia 1419 - CP 1427 - Ciudad de Buenos Aires Argentina - TE 4552-8360 Endereço eletrônico: beagreco26@yahoo.com.ar, beagreco@hotmail.com 
"No es al hombre al que hay que salvar sino al espacio que reúne a los hombres, única garantía para resistir la impronta del totalitarismo" Hanna Arendt (1951/1998)

"Nacer es buscarse un nombre; hallarlo, ya es morir" Edmond Jabés (1967/1991)

— l trabajo con sujetos e instituciones, con los sujetos en las instituciones - y con los procesos que entre ellos se producen, nos conduce a preguntamos - una vez más - si es posible seguir pensando los conceptos de identidad e identificación aludiendo a rasgos puramente "individuales" o desde uno solo de los lugares de la relación, ubicándose del lado de "un” sujeto (que aprende, enseña, interviene etc.) o de "una” institución (que educa, cura etc.). O bien, nos conduce -cada vez más- a pensar en espacios y lugares compartidos intergeneracionalmente, intersubjetivamente, en el lazo que arma lo social y lo individual a la vez, en la transmisión de una herencia, de un cultura y de una posibilidad de constituirse en ella como ser diferenciado.

Pensar la identidad - particularmente en las instituciones educativaspuede así llevar a ubicarse exclusivamente "en” los sujetos ("buenos” o "malos” alumnos, “adaptados” o "inadaptados”, “violentos”, “incapaces” o "capaces") o bien en las relaciones y los espacios entre jóvenes y adultos, en el "entre" las nuevas generaciones y las instituciones. Allí donde "lo que pasa”, seres humanos desde la propia humanidad de los adultos que los reciben, en el sentido de hacer humanos a "los que vienen", a los nuevos, a los "recién llegados”, como diría Arendt (1958/2005).

Pensar la identidad en estos términos conduce a hablar, a su vez, de los problemas que plantea este trabajo de humanizar, no en el sentido de

3 La idea de "lo que pasa" alude a aquello que ocurre y también alude a la transmisión, a lo que se pasa de una generación a otra. 
dificultades u obstáculos que dan trabajo y que deban eliminarse sino en el sentido de tensiones, de conflictividad inherente a la tarea, constitutiva, como paradojas propias de la humanización, como el proceso en el que se producen condiciones para "hacer lugar" a las generaciones más nuevas en el seno de una cultura que intenta perpetuarse reinventándose. Transmisión sin copia fiel.

Este trabajo de humanización que tiene que ver con la constitución de la identidad, no como algo individual sino como construcción conjunta adultos-niños/as y jóvenes en un grupo social, y con la "prestación de identidad" (Kammerer, 2000), por parte de los adultos hacia los niños, no se remite solamente a las funciones materna y paterna, a los vínculos primarios, familiares, sino que se refiere también a la posibilidad de que otros adultos, referentes, profesionales, animadores culturales, maestros, profesores, etc. se constituyan a su modo, en "postas parentales", "prestadores de identidad" (Kammerer, 2000), "pasadores de cultura” (Hassoun, 1994), en diversos espacios sociales e institucionales.

\section{Acerca de la identidad, las identificaciones y el yo}

La identidad es un concepto que ha preocupado históricamente al ser humano, el qué es esto que soy y que somos, cómo se construye lo específicamente humano, sobre quién es uno en relación al mundo, a uno mismo y a los otros. Es por esto que la cuestión de la identidad ha ocupado un lugar primordial en teorías filosóficas, psicológicas, pedagógicas, antropológicas, sociológicas, en el derecho, aún cuando no se utilice la palabra identidad para nombrar tal preocupación teórica o teórico-práctica.

La tradición moderna nos ha llevado a concebir de una determinada manera a la identidad, coherente con una idea de sujeto moderno. Este sujeto pensado en sentido cartesiano como dueño de sí mismo, pura conciencia, autocentrado, autosuficiente, sujeto del conocimiento, claramente recortado del mundo y de los objetos, a distancia, dueño de la naturaleza y de este mundo "sensible y engañoso", y a la vez recipiente de saberes. La identidad 
es, en este pensamiento, un estado fijo, un punto a alcanzar que se establece y escasamente se moviliza o diferencia de sí mismo, un lugar distinguible de otros al que se llega en determinado momento del desarrollo supuestamente natural del sujeto. Un lugar que, una vez obtenido, garantiza una respuesta cierta a la pregunta por quién soy o quién es el otro.

La respuesta esencialista a estas preguntas naturaliza identidades y las mantiene en singular (el niño es..., la mujer es..., el varón es..., el negro es..., el inmigrante es..., la mujer pobre es..., el adolescente villero es...) Toda singularidad puede ser metida a presión en algún molde de éstos forzando la coincidencia de cada uno/a con un modelo identitario predeterminado hegemónico. Así también hay identidades culturales, de género, etnia o clase que pueden ser colectivas pero que funcionan como grandes formatos adonde caben muchos sujetos pensados como idénticos (las mujeres, los pobres, los niños, los negros, los inmigrantes, los adolescentes, las adolescentes etc.) ¿Y quién define estas identidades?

El papel de las teorías no ha sido ingenuo en esta construcción de identidades desde esta manera de pensar.

Las teorías del desarrollo psicológico, por ejemplo, se han caracterizado y se caracterizan por describir y explicar un pretendido desarrollo natural (por etapas, edades mentales, características evolutivas etc.) para luego prescribir y normativizar delimitando lo que es normal o patológico, lo que debe ser o no ser de acuerdo a una pretendida descripción que, en realidad, es producción. Dice Erica Burman, una autora que trabaja en la línea de la deconstrucción de la psicología:

La ciencia promete orden al medir al individuo por vía de las investigaciones de la infancia, y la metáfora de la comprehensión se convierte casi literalmente en un proceso de apoderamiento del misterio de la infancia por medio de nuevas técnicas. (...) El control y la regulación de los elementos sociales considerados potencialmente ingobernables presuponían la manera de monitorizar a estas personas. La psicología individual surge para cumplir este papel de clasificación y vigilancia. El individuo psicológico era una entidad muy especificada y estudiada, cuyas cualidades mentales y cuyo desarrollo se entendían en virtud de la comparación con la población general. De esta forma el conocimiento de lo individual y de lo general iban de la mano: cada uno necesitaba del otro, y cada 
uno se definía en términos del otro. La separación entre la locura y la cordura, entre lo criminal y lo legal, y entre lo educable y lo no educable, cambió los criterios político-morales por una evaluación, igualmente criticable pero científica, del examen mental. (Burman, 1994, p. 7)

Las mediciones psicológicas llegan así a definir técnicamente la adecuación a la norma o su alejamiento, coeficientes intelectuales, edades mentales, logros madurativos, estados de salud o enfermedad, etc. por fuera de toda situación o contexto, midiendo capacidades aisladas de sujetos aislados para finalmente etiquetar identidades aisladas (la de la debilidad mental, inmadurez neurológica, retraso madurativo etc.).

Pensemos por ejemplo, los diagnósticos que se elaboran en los gabinetes escolares, que definen el destino de muchos chicos, destino que se va confirmando a medida que más y más profesionales garantizan científicamente, mediante sus informes, que ese niño o niña o joven "es” así y es difícilmente modificable. Pensemos, en este sentido, la marca que supone para la identidad de un "niño en problemas” (Baquero, 2000, p. 16), los informes profesionales que se elaboran sobre su escolaridad. Pensemos en la situación escolar de Adrián, un niño con "problemas de conducta”, que nos es presentada en tres informes de tres escuelas diferentes, el primero y el segundo hablan de él en términos exclusivamente de su conducta, de los desajustes de su conducta (como si tuviéramos un foco puesto únicamente en la persona de Adrián, más aún, sólo en sus gestos de indisciplina) dejando en la invisibilidad la situación escolar en la que Adrián se encontraba, esto es, lo que los adultos intentaron o realizaron en esa situación o cómo le hablaron, lo que le dijeron, cómo se dirigieron a él, qué produjeron en él. El tercer informe, abre el foco a una situación de habla, de gestos y de acciones, entre adultos y niño, lo muestra en relación con otros, con el aprendizaje, con los pares, consigo mismo, lo hace hablar. Focaliza en la intersubjetividad en la cual Adrián se constituye. Es en esta tercera escuela adonde el niño va a tener un lugar donde desplegarse a sí mismo, donde narrarse, donde poder decirle a alguien que él se considera "un tonto" y que no hay ninguna escuela donde podrá quedarse, puede decirlo allí porque en esta escuela se le ha hecho un lugar desde el comienzo, allí fue mirado y 
escuchado como una persona que "está siendo” y que no sólo está ya definida, en su deficitaria identidad, por sus "dificultades de conducta". Aquí, el informe no da una última palabra acerca de lo que el niño "es”; Adrián no "es" sus dificultades de conducta, es un sujeto que despliega lo que "puede ser" según las diferentes situaciones escolares adonde se lo invita a participar.

Una perspectiva que, en psicología, discute la idea de sujeto y de identidad como esencias naturales, que "son” más allá de toda situación, es la perspectiva socio-histórica y las teorías contextualistas o situacionales. Estas ponen en cuestionamiento que pueda pensarse a un sujeto y menos aún, definir su identidad, recortado de su contexto socio-histórico. Aquí, no se entiende al contexto como un entorno que explica por qué alguien es como es, o como un agregado que influye sobre la manera de ser de los sujetos, sino que le da al contexto y a la situación un lugar constitutivo. Dice Baquero:

El paradigma contextualista considera que el individuo como punto de partida de la explicación psicológica es un supuesto o mito de las perspectivas modernas que han visto bajo la figura del autor, de la autonomía entendida como escisión, de la independencia casi ontológica del sujeto en relación al entorno y el lazo social una figura normativa. (Baquero, 2002, p. 68)

Desde esta perspectiva se intentará ubicar al sujeto en el marco de relaciones, con otros, con un entorno, con un marco que da sentido a su situación y a su identidad en permanente redefinición.

La situación no opera como un contexto externo que decora, condiciona, acelera o enlentece un proceso de desarrollo que es atributo del individuo sino que el desarrollo, o el aprendizaje, es algo que se produce en situación y es la situación la que lo explica, aunque sus efectos, por supuesto puedan constatarse localmente también en los sujetos. (Baquero, 2002, p. 68)

Una perspectiva que ha conmovido la manera de pensar la subjetividad y discutido desde su formulación, de otra manera, una idea de sujeto y de identidad esencialista es el psicoanálisis, al menos, una lectura del psicoanálisis. Freud, partiendo de los síntomas, los sueños, los lapsus, y 
esos "restos” psíquicos que son las formaciones del inconciente, ha operado una división del sujeto, le ha sacado de su lugar de amo y dueño de sí mismo, desplazando una identidad que pretende hablar en su propio nombre. El yo - la instancia psíquica que da cuenta de la identidad- es para el psicoanálisis un yo escindido, conformado por fragmentos contradictorios, aspectos diferentes concientes e inconcientes, sirviendo a distintos amos (el ello, el superyo y la realidad) más que siendo “el dueño de casa”. La ilusión yoica es la ilusión de la unidad armoniosa, de la unidad identitaria, ser uno y sólo uno en todo momento y situación, como rasgo esencial. Se subvierte así la noción filosófica cartesiana de la relación con el conocimiento: el yo no es puro sujeto de conocimiento ni es pura conciencia, dirá el psicoanálisis. Está siempre en el límite, con un pie en los procesos concientes y otro en los inconcientes, tironeado por las exigencias de lo libidinal, lo que impone la realidad y la severidad de super yo.

El yo es, en cambio, objeto libidinal que se constituye en la relación con un otro que lo toma, en principio, como objeto; una relación en la que la mirada tendrá un lugar preponderante. "El yo es ante todo un yo corporal", escribió Freud (1914/1973) en "Introducción al Narcisismo”, es proyección mental de la superficie del cuerpo, imagen especular de una mirada. Es decir que la constitución de la identidad se va armando a partir de esa mirada sobre el cuerpo que otro le dirige y de una trama libidinal, pulsional, en donde el yo es proyección de esa imagen. Freud dará cuenta de esta imagen exaltada en el narcisismo, muy ligada a lo visible, al "estadio del espejo”, a los reflejos, a la ceguera, miradas, espejos, cuadros, pintura, visión (en textos como el de Leonardo, el de perturbaciones de la visión, el mito de Narciso etc)

La construcción del cuerpo - y de la identidad- depende, entonces, de una mirada de otro y de la propia, así la primera anticipa la propia imagen corporal (estadio del espejo) unificada. Campo de relaciones donde la presencia de otro se hace indispensable, identificaciones que definen el carácter constitutivo de la relación con ese otro.

El investimiento narcisístico, lo que constituye al yo como proyección del cuerpo, no puede explicarse a partir de un sujeto autónomo, encerrado 
sobre sí mismo, sino que se explica a partir de un orden que precede la existencia de un sujeto que devendrá tal por el hecho de ocupar un lugar para el otro, desde antes de su nacimiento.

En este sentido, la posibilidad de establecer lazo con el semejante no es un momento posterior a la constitución del yo sino que es él mismo constitutivo, es un modo de responder ante el enigma que plantea el deseo del otro, ofreciendo una imagen amable en la ilusión de colmar sus expectativas.

Encontramos entonces, una identidad descentrada: no pura conciencia ni conocimiento, una identidad como proceso y devenir: no como estado fijo y cristalizado ni etapa a la que se llega por un desarrollo progresivo, identidades múltiples en un solo sujeto: no una y sólo una y, una identidad como construcción a partir de un modelo libidinal: el yo como proyección mental y efecto de la interpretación de otro.

Es una psicoanalista, Aulagnier (1975/1988, p. 112) la que hablará con claridad de esta interpretación que constituye al sujeto. Ella dirá en su libro "La violencia de la interpretación" que hay un espacio adonde el yo debe advenir y que está hecho de palabras, es un espacio simbólico: “Todo sujeto nace en un espacio hablante”. Este espacio hablante es el hábitat donde el yo se constituirá, se forjará en relación a otros, para lo cual requiere de determinadas condiciones: que haya otros y que esos otros hagan lugar al sujeto en un discurso y en su deseo. Pensar en las condiciones necesarias para la constitución del yo, es lo mismo que Kammerer (2000) piensa cuando delimita de qué esta hecha la “deuda de vida”, concepto que abordaremos más adelante. Este espacio tiene dos organizadores esenciales: el discurso y el deseo de la pareja paterna.

¿Qué implica para Aulagnier esta violencia? En principio se trata de distinguir una violencia primaria de otra secundaria en la constitución subjetiva, una violencia -la primaria- que subjetiviza, que hace lugar al sujeto y por tanto, necesaria, que anticipa, que nombra, que funda, de otra violencia -la secundaria- desubjetivante, arrasadora, excesiva, que en lugar de hacer lugar, lo quita, lo borra, lo inunda, lo arrasa. La primaria será una 
violencia necesaria para permitir a alguien el acceso al orden de lo humano, precede al nacimiento del sujeto, es una especie de sombra hablada que la madre proyectará sobre el cuerpo del sujeto ni bien nace y ocupará el lugar de aquel al que se dirige. Esta violencia primaria, ejercida en actos y palabras se anticipan siempre a lo que el niño puede conocer de ellos, la oferta precede a la demanda, y "si el pecho es dado antes de que la boca sepa lo que espera” (Aulagnier, 1975/1988, p. 33), el desfasaje es aún mayor cuado se trata del registro del sentido.

La palabra materna derrama un flujo portador y creador de sentido que se anticipa en mucho a la capacidad del infans de reconocer su significación y de retomarla por cuenta propia. La madre se presenta como un yo hablante o un yo hablo que ubica al infans en situación de destinatario de un discurso, mientras que él carece de la posibilidad de apropiarse de la significación del enunciado (Aulagnier, 1975/1988, p. 33)

Es así que la psique del infans vivirá en el momento del encuentro con la voz materna: en este sentido es necesaria, porque garantiza la vida psíquica de un sujeto, es condición para la futura existencia del yo.

La violencia secundaria es, en cambio, violencia sobre el yo, se abre camino apoyándose sobre la primera pero es un exceso perjudicial e innecesario para su funcionamiento. Esta violencia es un ejercicio de poder abusivo, ya sea por parte de un yo ya constituido (como el de un padre o madre) como por parte de un discurso social que pretende oponerse a todo cambio, que sólo acepta perpetuar intactos sus modelos instituidos. La violencia secundaria suele ser desconocida para quienes la padecen porque a menudo se sustenta en un poder encubierto tras las "buenas" intenciones que imponen los modelos instituidos por "el bien del otro, de los jóvenes, de los débiles”, sin lugar alguno para la movilidad y la transformación. Sus efectos pueden ser así, en lugar de subjetivantes - es decir, “dadores” de lugar -, desubjetivantes - es decir, arrasadores de todo posible lugar propio donde desplegarse el sujeto, que debe ganarse y no sólo heredarse.

Podemos pensar que estos dos tipos de violencia no son solamente modalidades de la función materna sino que también pueden reconocerse en 
el funcionamiento de las instituciones, espacios sociales donde los sujetos pueden ser albergados otorgándoseles un lugar para habitar o pueden ser avasallados, imponiéndoseles un modelo al cual deben simplemente adaptarse, sin lugar alguno para la propia voz.

¿Cómo concebir en esta perspectiva al yo, la identidad, las identificaciones? Este espacio del que habla Aulagnier (1975/1988), adonde el yo debe advenir; es un espacio en el que uno no es aún, sino que va siendo, se va diciendo a sí mismo, va contando su historia y proyectándose en un proyecto a futuro, se va otorgando sentido en relación al espacio de otros, los adultos que habilitan ese lugar.

Dice Aulagnier (1975/1988, p. 147) que "El Yo no es más que el saber que el Yo puede tener acerca del Yo”, saber que incluye lo que el campo social, cultural, al que pertenecen los padres, espera de él, del cual, a la vez, el niño deberá apropiarse y enunciar con su propia voz, con sus propias modulaciones, según su deseo y sus anhelos, independientes del exclusivo veredicto parental. La autora ubica aquí lo que llama, proyecto identificatorio, que consiste en la posibilidad de que el yo construya un saber sobre el yo futuro y sobre el futuro del yo, un yo futuro que renuncie a la certeza, que represente una esperanza, designando su objeto en una imagen identificatoria valorizada por el sujeto y por el conjunto social. Esta imagen se constituye en dos tiempos, cuando el niño puede enunciar "cuando sea grande, yo...” y cuando más tarde dice “... seré esto”.

Conjugar ese tiempo futuro en un proyecto identificatorio es garantía de sostén del yo, es indispensable poder proyectarse para sostener la propia identidad actual y futura. Pero la imagen que se desea alcanzar no puede coincidir con la imagen que el sujeto se forja acerca de él en su presente. Para ser, el yo debe apoyarse en su anhelo pero distanciarse de él, debe presentar alguna carencia, una meta por la cual seguir sabiendo de sí mismo, aún no alcanzada.

Estas aportaciones permiten seguir pensando ya no sólo el lugar de los padres en la constitución subjetiva, sino el de los adultos referentes de diverso tipo y las instituciones en las que se encuentran con los jóvenes en el 
marco de vínculos y procesos de subjetivación. En ese sentido, es que Kammerer (2000) subraya el papel de los prestadores de identidad.

\section{Prestadores de identidad y deuda de vida}

Identidad es huella, es nombre, es lo que permite que la gramática de lo singular sea inscripta y reconocida en una gramática de lo plural. Es herencia y creación, continuidad y ruptura. Deseo de reconocimiento. Identidad es el otro nombre de la alteridad. (Frigerio, 2003, p. 147)

Cuando Kammerer (2000) propone pensar el lugar de los padres y otros referentes adultos como "prestadores de identidad", nos conduce a pensar que la identidad se va armando con fragmentos prestados por otros y concebir este "prestar" como un acto en el cual los "mayores" se hacen cargo del pago de una deuda que los que llegan al mundo heredan por haber recibido la vida. Traer un hijo al mundo es asumir la responsabilidad de pagar esta deuda $\mathrm{y}$, en un sentido general, la deuda de vida es la responsabilidad de todo adulto ante las nuevas generaciones.

La deuda de vida es la humanización de la vida biológica, está hecha del entramado mismo de las funciones materna y paterna, es sostener y es dar la posibilidad de alejarse, de perderse sin caer en el vacío, es protección y aventura, es lazo familiar y encuentro con otros ajenos, extranjeros. El pago de una deuda de vida que se recibe en un tiempo de la vida nos humaniza, pero es una deuda que tiene vencimiento, no es eterna, encuentra su límite cuando el sujeto deja de esperar que otros paguen por él y se hace cargo de sí mismo.

No hay sujeto humanizado sin deuda, por otra parte, en la filiación: simplemente porque las generaciones sólo se suceden transmitiéndose una deuda, la de tener que humanizar la vida que no ha sido dada a cada recién nacido más que bajo su forma biológica. Si los humanos no pueden realizar este trabajo, entonces ocurre el autismo o bien la psicosis, es decir, en el extremo, la falta de palabra propia - psíquicamente hablando-. Si el niño es recogido por lobos, se vuelve un niño-lobo, como ya ha sido descrito: el 
solo programa genético es incapaz de humanizar la vida. Ello requiere de un entorno humano, animado por el sentimiento de una deuda que debe pagarse. La deuda simbólica es lo que los humanos deben a la vida para que ésta se transmita bajo su forma humanizada, de generación en generación. Y ello demanda "prestadores" dispuestos a donar sin pedir nada a cambio.

Este lugar de adulto, de prestador de identidad, dice Kammerer (2000), puede ser ocupado por diferentes figuras -no sólo las parentales- que incluyen a maestros, profesionales, referentes diversos. Es un lugar complejo, desde donde se da y también se limita, se ofrece y se deja en libertad, se sostiene y se genera la autonomía. Apertura a la emancipación.

Kammerer es un psicoanalista francés que trabaja con adolescentes y adultos llamados "violentos", que se ven inmersos en situaciones de delincuencia, drogadicción, etc., trabaja con ellos en instituciones cerradas, institutos de menores e incluso en cárceles, adonde la violencia se repite y muchas veces, se multiplica. El se pregunta entonces: ¿De dónde proviene la violencia que habita a ciertos adolescentes? ¿Qué escenarios psíquicos los condena a ella? ¿Y desde qué historia relacional ella se les ha impuesto como último recurso? ¿Estos adolescentes requieren métodos de socialización excepcionales o bien de cuidados psíquicos particulares? ¿ $\mathrm{Si}$ su organización psíquica permanece ligada al tiempo de la infancia, fijada a situaciones en las que se les ha negado un lugar, por medio de qué relaciones inéditas se les permitirá ponerla en movimiento?

Para Kammerer, acercarse a la personalidad de estos adolescentes, a su identidad sellada como "adolescentes violentos", lleva a pensar inevitablemente en su historia, en los padres que han tenido, en los padres que deberían haber tenido, en los padres que podrían aún encontrar y también en los padres que podrían ser ellos mismos en un futuro. La función-padre o madre no es solamente aquella que ejerce quien dio la vida biológica al niño, como veremos, puede no ser ejercida por el padre biológico y ser distribuida entre diferentes figuras adultas significativas.

Están, por un lado, los padres biológicos, los que han dado la vida biológica pero que pueden no haberse hecho cargo del pago de la deuda 
simbólica, la de humanizar la vida. Su responsabilidad no ha sido asumida y su historia como padres no se inscribe simbólicamente en la vida de sus hijos. Estos tiempos nos traen numerosos relatos en los que los orígenes son desconocidos o han sido ocultados al niño. Casi siempre se abre camino la necesidad de conocer esos orígenes, expresada de las más diversas maneras. Las huellas vacías de una historia desconocida no dejan de demandar ser escritas, sobretodo cuando el o la adolescente se acercan, en la adolescencia y la juventud, a la posibilidad de constituirse padres o madres y ser ellos los iniciadores de la historia de otro ser.

Los padres de la realidad son los que se han hecho cargo de la deuda de vida contraída en la concepción de su hijo o hija o bien en su adopción, quienes ejercen las funciones de padre y madre. Estos son los que asumen el trabajo de humanización de la vida biológica. Los que prestan su cuerpo, sus palabras, sus gestos, dan su mirada, anticipan proyectos para que el nuevo ser sea.

Las imagos parentales son las que habitan el interior de los adolescentes. Organizan el funcionamiento psíquico que los conducirá a la violencia o a una vida en comunidad con otros. Estas imagos internas han sido heredadadas interpretando, interiorizando o incorporando los hechos y gestos de sus padres reales, pero también pueden arrastrar consigo los rastros de los procreadores desconocidos, aún sin saberlo. Pueden ser portadoras de vida o mortíferas, conducir a un encuentro posible con otros o a la violencia. Se construyen también del imaginario del niño acerca de generaciones anteriores: afirma Kammerer (2000) que cuando éstas han vivido graves traumas y cargado fantasmas demasiado mortíferos, la vida donada no aparecerá vivible más que al precio de reparar la historia de los ancestros. Es generalmente en la adolescencia que este mandato inconciente se manifiesta, a veces, de forma brutal y cuando se experimenta la urgencia vital de desprenderse de él para dar sentido a la propia vida.

Están también aquellos que han podido y pueden ser todavía postas parentales: miembros de la familia, educadores, psicólogos, animadores, jueces de niños, referentes adultos que se hacen cargo de parte de esa función 
materna/paterna ofreciendo su diversidad en palabras y gestos, abriendo otras posibilidades, inaugurando novedad en los modos de relacionarse. Dice Kammerer (2000) que es a partir de estas postas o relevos que estos adolescentes renovarán sus imagos internas y se transformarán en sus propios padres y madres, haciéndose cargo de sí mismos. Es la posibilidad de que existan estas postas parentales la que alienta a pensar que nuestros oficios y las instituciones donde los desplegamos, tienen un sentido profundo en la transmisión y humanización de la vida singular y en comunidad.

Además, están las figuras parentales. Son los hombres y mujeres que los adolescentes interpelan porque esperan secretamente encontrar cerca de ellos un poco de las funciones parentales que les han faltado, a riesgo a veces de provocarlos violentamente o de ignorarlos con insistencia.

Hay otro padre, el padre por venir, que el o la adolescente construye dentro de sí mismo al construirse como sujeto, o el que no podrá construir jamás por no habilitarse a sí mismo para ello. Este padre o madre que será o podrá ser tiene mucho que ver con la deuda de vida que cada uno experimenta en tanto deuda saldada o aún por pagar. Cuando se vive con el sentimiento de esperar eternamente que alguien pague esa deuda, las posibilidades de hacerse padre o madre - en el sentido de hacerse cargo de la humanización de un nuevo ser- se abren con dificultad. Más aún, este "padre por venir” no sería sólo la posibilidad de convertirse efectivamente en padre o madre, sino la puesta en marcha de la propia emancipación, ese proceso que otros autores conciben como el "soltarse de la mano" (abandonar la categoría de mancipia, lo que se tiene como una cosa en propiedad (Vico, 2001)), el liberarse de un dominio ejercido por otro y asumirse a sí mismo como dueño de la propia vida, una "salida de la minoridad” (Foucault, 1994) que supone, fundamentalmente, un cambio de actitud ante uno mismo, ante los otros, ante la comunidad.

¿Cuál es el lugar, entonces, para este autor, de los posicionamientos adultos en lo cotidiano? ¿qué se demanda a ese "lugar de adulto”? En principio, su planteo es que son fundamentales, no sólo para constituir a un sujeto en su infancia y adolescencia sino para ayudarlo a transformarse, a 
recrear vínculos. Afirma que cuando la asimetría que se establece es justa y las prohibiciones respetuosamente ubicadas, cuando la ley simbólica está correctamente representada por reglas de vida que garantizan protección, placer, éxito, firmeza y libertad... entonces los jóvenes y los adolescentes violentos, en particular, comienzan a preguntarse por qué maltratan los lazos que se tejen a su alrededor. En tanto el encuadre de vida institucional se mantiene tan incoherente, mortífero o traumático como lo han sido las relaciones familiares de muchos de estos jóvenes, no podrán jamás tener deseos de transformarse.

Precisamos, entonces, desarrollos conceptuales sobre los cuales hacer reposar dispositivos institucionales que ofrezcan a los adultos mayor serenidad ante los comportamientos violentos ya que, una vez pasada la tormenta, es posible hacer algo más que castigar o excluir, afirma Kammerer (2000). Y pensamos, a partir de sus palabras, más allá del castigo o la exclusión de los adolescentes "violentos", en tantos jóvenes castigados de distintas formas más o menos visibles y excluidos de tantos espacios sociales en nuestro país.

Dice Kammerer (2000) que su recorrido profesional lo ha llevado a trabajar de manera dual en la cura analítica y a construir, en los lugares donde viven ciertos pacientes, un encuadre y un contexto relacional que producen efectos de estructuración psíquica. Son los dispositivos clínicos de la institución que deben permitir el desarrollo, entre pacientes y "curadores", de juegos relacionales nuevos y transformadores de experiencias traumáticas anteriores. Los pacientes experimentarán una solicitud y un interés real que no han percibido en otros contextos, y también recibirán prohibiciones que imponen y permiten la humanización pulsional.

Las prohibiciones estructurantes -la ley simbólica-, el niño las integra en principio, en su familia. La institución que releva a esta familia las ofrece a su vez garantizando a quien consiente en realizar renunciamientos pulsionales, satisfacciones de un nivel más alto, aquellas del lazo social, de la vida en comunidad. Estas mismas pulsiones deben poder satisfacerse en nuevas realizaciones de deseos, lícitas esta vez. Esto es lo que se llama 
sublimación o humanización de las pulsiones. Esto hace que la institución garantice al sujeto mayor consideración hacia otros y hacia sí mismo, mayor poder sobre su propia vida. Una institución, educativa o terapéutica, que demande renunciamientos y sublimaciones pulsionales sin ofrecer, como contraparte, el reconocimiento y los medios para una autonomía creadora nueva, no obtendrá lo que espera. Los jóvenes se rehusarán a integrar la ley simbólica que se vuelve así, nuevamente rechazada.

Un modelo de inserción social, para sostener la humanización, debe ofrecer reglas de juego, leyes e ideales que sean introducidos por la ley simbólica: límites que confirmen al sujeto humano su respeto ante las prohibiciones, leyes que le hagan escapar al riesgo de la descarga pulsional brutal, perversa y degradante. Este modelo de inserción debe gratificarse con nuevos derechos y nuevos medios para vivir su vida, sus amores, y para transmitir la vida. Cada uno vivirá esta inserción en diversas dimensiones y el sujeto podrá manifestarse a partir de modos que incluyan múltiples pertenencias y que no sean alienantes, ya que ellas no serán definitivas, terminadas, irreversibles.

Estas pertenencias permanecerán siendo plurales, soporte de lazos que integren los encuentros y las ausencias. El sujeto será el regulador de eventuales conflictos entre estas diversas pertenencias. A través de ellas negociará sus solidaridades sociales o familiares y experimentará, el sentimiento de su identidad cambiante. Estas pertenencias negociadas, dado que aportan solidaridades mutuas, no se transformarán en pertenencias fusionales, agobiantes y reductoras de diferencias personales. Y la pertenencia a diferentes grupos sociales es una manera de definir la propia identidad.

La deuda de vida es entonces un trabajo a hacer no sólo por los padres biológicos o reales, es un trabajo a asumir y distribuir entre los “relevos", las "postas", los adultos que reciben a las nuevas generaciones, de distintas maneras y en diferentes ámbitos, es deuda de vida y debida, según las palabras de Graciela Frigerio (2003, p. 146):

Responsabilidad de solicitud, institución de las limitaciones y prohibiciones fundantes que hacen al sujeto y a las sociedades y transmisión de lo necesario para 
que el otro se inserte en la sociedad constituyen para Kammerer (2000) los componentes de lo que denomina deuda de vida y que proponemos escuchar y significar como deuda de-vida y como deuda debida. (...) Para nosotros está claro que nuestros oficios trabajan sobre el registro de la deuda de vida significada como deuda debida. La que la sociedad contrae por su carácter de humana con todos los que ejercen el oficio del vivir, que la lleva a ofrecer un apuntalamiento allí donde no hay nada que sostenga, allí donde lo que sostiene está, pero el sujeto no puede apoyarse, allí donde está y el sujeto puede apoyarse, pero donde la cuestión del otro sigue manteniendo vigencia, dado que, al decir de Rancière: “¿Qué es un proceso de subjetivación? Es la formación de un uno que no es un sí mismo, sino la relación de un sí mismo con otro" (1998).

Volvemos así, al comienzo de este texto, cuando proponíamos pensar que la identidad no es hablar de uno solo sino siempre de dos, o mejor aún, del espacio que los reúne y los transforma. Los procesos de subjetivación, entonces, aquellos que "hacen a un sujeto", son la relación de un sí mismo con otro, la búsqueda permanente de un nombre, de nombrarse a sí mismos en relación a otros.

\section{Buscarse un nombre. Una cuestión de emancipación.}

Afirma Jabés (1967/1991, p. 14) en nuestra cita inicial que "nacer es buscarse un nombre, hallarlo ya es morir". Paradojas de la transmisión humana: un nombre nos es dado al nacer pero sólo será nuestro si lo hacemos propio a través de la marca de nuestra escritura, si lo articulamos con la propia voz, si lo buscamos en el infinito entramado con otros, en los vínculos que nos constituyen y que constituímos. Caminos de la emancipación, que se encuentran o se inventan y recorren tanto individual como colectivamente, en procesos personales y también políticos.

Podríamos señalar de manera renovada la paradoja ya enunciada: nadie puede ser emancipado por otro pero a la vez, nadie se emancipa solo. Si nos remitimos a la concepción de sujeto que recorríamos antes, la del sujeto situado, en relación con otros y con el mundo, enlazados por el lenguaje, podemos pensar que el lugar de la emancipación es siempre en una relación con otro, es en el lazo que libera, pero no en el sujetamiento que 
inmoviliza, se produce en distintos espacios sociales pero no tiene un espacio que le sea propio, funciona inversamente a la maquinaria social pero no la sustituye, requiere de la palabra de otro pero supone el rechazo a la repetición de esta palabra. Es así como Rancière nos lo hace pensar desde la filosofía política en relación a procesos de subjetivación en el marco de movimientos políticos emancipatorios. "Sólo el que abandona los mecanismos de la máquina social tiene la oportunidad de hacer circular la energía eléctrica de la emancipación” (Rancière, 1987, p. 179)

Jacques Rancière nos ofrece numerosos ejemplos de ruptura de los mecanismos de esta máquina social a lo largo de sus obra: el propio Joseph Jacotot, el "maestro ignorante” (Rancière, 1987) proponiendo enseñar lo que ignora sin explicar absolutamente nada ante una sociedad moderna, explicadora por excelencia; los obreros de "La noche de los proletarios" que en los años 1830 deciden romper el círculo de sueño y vigilia, trabajo y reposo, y trastocar el descanso nocturno en veladas de lectura y escritura, discusión y aprendizaje (Rancière, 1981); el doble silencio que los "Canuts de Lyon” intentan romper cuando buscan un nombre genérico para calificar al oficio y a los obreros de la fábrica lionesa (Rancière, 1985); el filósofo plebeyo Gabriel Gauny (1983) quien, rompiendo la regla que Platón impusiera a los artesanos, aquella de la falta de tiempo para otra cosa que no sea el trabajo, decidió hacer otra cosa además de su trabajo, aquello destinado a otros: el pensamiento y la poesía, por nombrar algunos.

Todos ellos nos hablan de una inscripción en la palabra diferente, una palabra que irrumpe y nombra nuevas identidades, rompe el consenso, rechaza los roles del diálogo tradicional, que da "voz" y "parte", que subjetiviza, que desidentifica, que descoloca creando igualdad allí donde hay desigualdad. Un sujeto de palabra siempre potencial y que no termina nunca de actualizarse, como la igualdad. Una palabra que es acto de emancipación porque es en ese mismo acto que se constituye el sujeto, "aprendiendo a ser un igual en una sociedad de desiguales” (Rancière, 1987).

La emancipación es en sí misma una salida de la minoridad, según lo decía Kant en el texto que retoma Foucault: “¿Qué es la Ilustración?” 
(Foucault, 1994), salida de la minoridad que supone una posición diferente ante la autoridad y es, en palabras de Foucault (1994), lo que define una “actitud de la modernidad”, un atreverse a pensar por sí mismo en palabras kantianas, otro modo de relación con la verdad, otro modo de vincularse la voluntad. La diferencia que se establece entre el uso privado de la razón y el uso público de la razón, entre el "obedezca sin reflexionar" y el "obedezca y reflexione” (Kant, 1784). En este punto también se habla de una máquina social que demanda individuos-engranajes de sus mecanismos -mediante un uso privado de la razón- por oposición a una salida del circuito de la máquina social haciendo "circular la energía eléctrica de la emancipación”, tal como lo decían Rancière (1987), equivalente al uso público de la razón. ¿Pero cómo se alcanza este uso público de la razón, este pensar por uno mismo? ¿De qué manera se sale de la minoridad? ¿Son estos estados claramente diferenciados y factibles de alinear en una continuidad progresiva? ¿Supone la emancipación un rechazo a toda autoridad?

En su introducción al texto L'émancipation, Navet (2002) dice que es G. B. Vico quien ofrece la voz más directa sobre el término emancipación:

El filósofo napolitano explica que en el tiempo en que se organizaron las primeras familias patriarcales, los hombres se expresaban solamente por medio de gestos, símbolos materiales o por una combinación de los dos. El gesto de tomar con la mano (manus capio) significa tomarse de..., apoderarse, tomar poder sobre..., entonces: volverse propietario de... "Las primeras tierras cultivadas fueron las primeras 'presas' (praedae) del mundo; de allí viene que la primera dominación se ejerció sobre tierras de este espacio que fueron por este motivo llamadas manucaptae en el antiguo derecho romano. (...) Estas tierras llamadas manucaptae debieron ser las primeras en ser denominadas mancipia (...)” Pero la acción de tomar o de capturar con la mano no se detuvo en las tierras, en los objetos inanimados y en los animales. Los errantes que se refugiaron en la casa de los padres fundadores "a fin de salvar su vida y, habiendo sido recibidos a cambio de su vida, fueron obligados a cultivar los campos de sus padres", fueron asimilados a cosas o a animales considerados entonces como seres sin alma y ubicados en la categoría mancipia, de las cosas tenidas con la mano. La emancipación es el esfuerzo de estos famoli para liberarse del dominio que pesa sobre ellos (Navet, 2002, p. 7) 
En relación a la sujeción a una autoridad y el sujetamiento, en esta categoría de mancipia, Lyotard, por su parte, se refiere al mancipium al definir una determinada concepción de infancia:

Por infancia entiendo que nacemos antes de nacer para nosotros mismos. Y, por lo tanto, nacemos a través de otros, pero también para otros, entregados, sin defensa, a los otros. Estamos sujetos a su mancipium, que ellos mismos no pueden evaluar. Porque, aunque sean madres y padres, ellos mismos son también infantes. Ellos no están emancipados de su propia infancia, de la herida de la infancia o del llamado que ella lanza. (Lyotard, 1990, p. 18)

Hay evidentemente una estrecha relación entre emancipación y “desujetamiento”, liberación de una autoridad en el sentido de tutelaje o apoderamiento, entre emancipación e interrupción del dominio de uno sobre otro, entre emancipación y liberación de un poder que no deja ser, entre emancipación y salida de un estado de minoridad o infancia entendida como sujetamiento, edad en donde no se razonaría por uno mismo ni se asumiría un lugar de autonomía. Emancipación es así un movimiento que aleja, un proceso que desliga, en una relación de poder, al sujeto heterónomo de aquel de quien depende.

Sin embargo, la liberación de la relación con una autoridad que piensa, decide, hace, por uno, no es solamente una liberación en relación a una instancia externa, instancia que sujeta al sujeto por fuera del sujeto mismo, sino que es movimiento a la vez externo e interno, que transforma y constituye al sujeto en el mismo proceso emancipador.

Es que emancipación es reformulación, cuestionamiento de relaciones y de sujetos, des-aprendizaje, desnaturalización de hechos y de estados de hecho, giro en el presente que da a ver un pasado y un futuro diferentes, a su vez, no naturales, como lugares de escritura de otra historia del sujeto.

\section{Un sujeto emancipado. Cuestión de temporalidad.}

El sujeto emancipado no existe de antemano, no preexiste, sino que instituye su lugar emancipándose. Dice Navet (2002, p. 8): 
La emancipación tiene su origen en el rechazo a un estado de hecho; designa, como tal, el movimiento por el cual se abren un tiempo y un espacio que son irreductibles al tiempo y al espacio naturales. Hace, en otros términos, escapar a la repetición en el lugar de lo mismo comprometiendo un tiempo lineal y orientado tanto como un espacio donde la misma relación con la naturaleza se encuentra mediatizada por relaciones interhumanas. Sería un error encarar ese tiempo sólo en su dimensión de futuro; su despliegue hace aparecer un pasado que parece haber estado siempre allí, como a la espera de ser revelado, pero que es como el complemento obligado de lo que viene de surgir como presente y como futuro.

La temporalidad se ve conmovida por el proceso emancipador, el devenir de la historia para el sujeto adquiere otra textura, otra dimensión, otra complejidad. Se trastoca lo ya dado o lo que nunca será dado, como destinos inexorables, mandatos sociales o subjetivos indelebles. La emancipación instaura tiempos y espacios humanos en los que se revierte un estado natural de las cosas en donde éstas son concebidas como lo que son, como supuestamente siendo "esencias" que se definen externamente a partir de un tiempo lineal que no se deja transformar. Pone en movimiento de otro modo, ya no lo que el sujeto "es”, sino lo que "va siendo", a través de las preguntas sobre sí mismo, sobre la historia, la sociedad, las relaciones entre humanos. "Se puede aventurar que el tiempo de la emancipación es el único tiempo propiamente humano” (Navet, 2002, p. 10).

Es que no se trata de un mero pasaje de un estado a otro, social o subjetivo, tampoco de una evolución que progresa y se instala para siempre, como un logro alcanzado: de estar sometido a estar emancipado y... "ya está”, una nueva identidad se fija; en cambio, la emancipación se vuelve devenir emancipatorio, obliga a una reformulación permanente de lo que en las relaciones humanas tiende a naturalizarse, a volverse nuevo estado de hecho. Como trabajo permanente, entonces, "Todo movimiento de emancipación apunta a modificar las relaciones fundamentales entre los humanos y las modifica ya por su sola existencia.” (Navet, 2002, p. 10). Es que toda reivindicación social o subjetiva conlleva nuevos modos relacionales que modifican tanto el lugar de quien se reivindica emancipándose como de aquellos a quienes se les ha dirigido un reclamo, trabajo que no cesa de ocurrir y de demandar nuevas acciones del/los sujeto/s emancipado/s.

Es así que éste - el sujeto emancipado- no es un sujeto autosuficiente, desligado de toda ligadura, autoengendrado y "libre" del entrelazamiento de 
las relaciones con otros. Por el contrario, el sujeto emancipado sostiene su preocupación constante por los otros, por los modos de relación con otros que no conllevan sujetamiento ni “atontamiento", en palabras jacotistas.

Decíamos anteriormente que el sujeto emancipado no preexiste al movimiento emancipador en sí mismo, ni habría ninguna condición humana natural que deba "despertarse", "iluminarse”, ser sacada de algún fondo oscuro y reprimido o ser liberada de ataduras culturales determinadas. "No se trata de decir que la emancipación apuntaría a realizar una cierta naturaleza humana, ya que a la inversa, es el movimiento emancipador que libera, que crea, virtualidades humanas que sólo aparecerían o no existirían sin él" (Navet, 2002, p. 10). En Jacotot (1829), el maestro ignorante, la resistencia a homologar igualdad y progreso, la insistencia en poner de manifiesto incluso, su oposición, nos habla de la emancipación que propone su anti-método. No es la instrucción la que emancipa, no es la búsqueda de la igualdad como horizonte permanente siempre alejado la que produce el progreso, por el contrario, es el rechazo a ser "inferiorizado" en relaciones de educación "progresistas", lo que emancipa y crea al sujeto en el mismo movimiento emancipatorio, en un lazo con otro, un igual, un maestro emancipado.

Así, volvemos a nuestras consideraciones sobre el sujeto, en tanto la emancipación nos coloca ante un modo de pensarlo, lejos de concepciones sustancialistas, autosuficientes y autofundadas. Volvemos también a un modo de pensar el acto de palabra como acto de subjetivación.

El proceso emancipatorio entendido de esta manera, como proceso y no como sucesión de estados, como desnaturalización de espacios y de tiempos humanos, como temporalidad que reformula la relación entre presente, pasado y futuro, así como las relaciones con los otros, entendido también como trabajo de humanización que instaura al sujeto en el mismo movimiento emancipatorio, nos vuelve a conducir a la pregunta por la constitución de la identidad, de la subjetividad y su lugar en el devenir de lo humano tanto en lo individual como en lo social, a través de la transmisión. Cuestión que abordaremos desde otro lugar, a través del maestro ignorante y su autoridad, la que convoca nuestra reflexión. 
Acerca das Identidades e Situações. Pensamentos sobre a Emancipação

\title{
Jacotot, Rancière, la emancipación y la autoridad. Reflexiones sobre la transmisión
}

\author{
“(...) ese niño será él mismo \\ emancipado, ya que piensa sin \\ explicaciones” (Jacotot, 1829, p. xli)
}

Este texto de Jacques Ranciere relata la aventura intelectual de un pedagogo francés del siglo XIX, Joseph Jacotot, a quien el azar colocó en el lugar de una experiencia pedagógica inédita: enseñar algo que ignoraba. Enseñar a alumnos flamencos, cuya lengua no conocía y quienes no conocían la suya. Igualdad entre maestro y alumnos en el desconocimiento mutuo de sus lenguas. Es así como Jacotot encontró un libro, un Telémaco bilingüe, que colocó en manos de sus alumnos con la indicación de leerlo, repetirlo, asociando, comparando, escribiendo lo que pensaran. Los resultados lo sorprendieron, sus alumnos aprendían francés sin que él les hubiera explicado una palabra. La experiencia lo conmovió de tal manera que hizo oír su voz escandalizadora: proclamó que los ignorantes podían aprender solos sin maestro explicador y que un maestro podía enseñar aquello que ignoraba. Se hizo, entonces, oír con fuerza ante un "siglo de las luces” que no quería escuchar, justo en el momento en que el afán pedagógico de una sociedad en vías de transformación se proponía "igualar las desigualdades” a través de la instrucción pública, el método perfeccionado, el orden progresivo, la explicación sin límite desde el saber de los maestros a la ignorancia de los alumnos. Jacotot interpuso su noticia disonante, advirtió que "la distancia que la escuela y la sociedad pedagogizada pretenden reducir es aquella de la que viven y la que, por tanto, no cesan de reproducir” (Jacotot, 1829, p. iii). Insistió en que su “antimétodo” sólo supone la verificación de un principio, el de igualdad, que no es meta a alcanzar ni tiempo por venir y que todos los seres parlantes compartimos una misma inteligencia que debe actualizarse cada vez, en el trabajo de aprender y relacionar, hablar y adivinar, un trabajo que rechaza jerarquías de inteligencias entre maestro y alumno y conecta voluntades. 
Rancière (1987) habla, en su libro, a la par de Jacotot, sus voces se confunden relatando una historia que interrumpe nuestras certezas y propone, una y otra vez, la interrogación fundamental por lo que saber, enseñar y aprender quieren decir.

Una nueva pregunta se abre, entonces, ¿todo proceso emancipatorio implica un rechazo a la autoridad "del que sabe”?, ¿existe una oposición entre emancipación y autoridad, en términos del “maestro ignorante”?.

Es interesante seguir, en este sentido, la lógica de la relación que establece Jacotot entre emancipación, autoridad paterna/materna -función paterna, podríamos decir, en un sentido genérico- y transmisión de padre a hijo. Si bien la emancipación supone -como lo afirman los diccionarios- una liberación de la tutela paterna, Jacotot apuesta a la emancipación del propio padre y al lazo con su hijo, como lugar privilegiado desde donde es posible generar condiciones para la emancipación del hijo, por fuera de las instituciones de la instrucción.

\begin{abstract}
Un padre está emancipado cuando ha reflexionado: primero sobre su profesión y sobre la manera en que la ejerce; segundo sobre los hombres que lo rodean, para saber si se le parecen por la inteligencia, si tienen los mismos vicios y las mismas virtudes. Finalmente cuando ha verificado en qué sentido es verdad que todo está en todo. Un padre emancipado puede emancipar a sus hijos, exigiendo que hagan, sobre lo que sea, lo que él mismo ha hecho. He ahí todo. (...) la masa de los individuos de la clase pobre no es del todo libre. La gran mayoría está obligada a soportar el yugo de los examinadores embrutecedores, y en consecuencia, a llamar a los explicadores en ciertos casos. (...) Sin embargo, nada impide que se emancipe a los hijos desde su infancia. (...) Educados en la reflexión, reflexionarán sobre las explicaciones que se verán forzados a escuchar más tarde; pero ellas no los embrutecerán porque sabrán que no son necesarias. (Jacotot, 1829, pp. xlii, xlv)
\end{abstract}

Así, la emancipación es aquello que permite que todo hombre de pueblo reconozca su dignidad de hombre, valore su capacidad intelectual y decida cómo usarla, haciendo que sus hijos produzcan de igual manera su propio proceso emancipatorio.

Jacotot se muestra preocupado así, por la emancipación y su transmisión, ya que no es en los lugares donde se instruye donde la maquinaria social de la desigualdad se detiene, no es en la escuela - para él- 
donde se emancipa ni donde la explicación deja de crear inferioridades y reproducir el embrutecimiento. El espacio familiar se vuelve así, un lugar posible, donde la transmisión de padre a hijo se constituye en la vía privilegiada "por donde circula la energía emancipatoria”. ¿Pero de qué relación paterno-filial se trata? ¿de qué tipo de autoridad paterna? Para Jacotot, ésta no está desvinculada de una cierta posición del padre en el mundo del trabajo, posición a través de la cual el artesano o el campesino reflexionan sobre sus herramientas, sobre el modo en que las emplean, se inventan otras... sin explicaciones de nadie, verificando que cuentan con la misma inteligencia que los demás. "Cuando se ha reflexionado, sin explicaciones, sobre el parecido moral e intelectual que existe entre todos los hombres, se está emancipado" (Jacotot, 1829, p. xli). La firme creencia en la igualdad de "cualquiera con cualquiera”, sostenida por el padre se transmitirá a su hijo, casi sin palabras, la emancipación circulará de uno a otro.

Cuando el niño le haya respondido alguna cosa que le parezca razonable al padre emancipado, este niño estará él mismo emancipado, porque piensa sin explicaciones. Cada palabra del libro le proveerá de preguntas al padre. El hijo escribirá las respuestas. El primer libro es inagotable. Sus ejercicios deben hacerse todo el resto de la vida. (Jacotot, 1829, pp. xl, xli).

Jacotot busca así en la función paterna (en el ámbito familiar) una función garante de la emancipación de los sujetos, un lugar de terceridad, una referencia que no perpetúe la dependencia sino que abra a la autonomía del pensamiento. Jacotot desconfía de que esta función de tercero, referente, garante de constitución subjetiva se encuentre en las instituciones educativas, entre los maestros, profesores y doctores, en los ámbitos académicos, en la autoridad de los sabios. Sospecha que la propia sujeción de estas autoridades del saber a un orden social hecho de jerarquías - y la convicción en su propia superioridad- no hará más que garantizar la “inferiorización” de los ignorantes y la perpetuación del orden de la desigualdad.

Rancière tomará esta inversión de los roles entre la familia y la escuela para pensar el despliegue del proceso emancipatorio, en el cual no se trata de crear sabios sino de "convencer" a quienes se sienten inferiores de que 
tienen un poder de pensamiento propio, que no son inferiores ni deben menospreciarse a sí mismos, que son iguales. Se trata de producir hombres emancipados diferenciando claramente el método emancipador del método social. Hombres, mujeres y niños que piensen sin explicaciones.

Jacotot y Rancière, insisten, sólo hay que reconocer un principio de igualdad "de cualquiera con cualquiera" y desestimar toda superioridad, todo saber proveniente de un maestro, todo orgullo u omnipotencia, toda autoridad que se erija en dueña del saber y poder. Pero para ello es necesario, aunque parezca contradictorio, que haya una autoridad, un lugar tercero, un garante, una función paterna o función de maestro ignorante que oficie de mediador para que la igualdad se verifique. Jacotot la ubica en el lugar del padre artesano o campesino que, emancipado él mismo puede transmitir la emancipación al hijo. Puede advertirlo de que la explicación sin fin embrutece, adormece la posibilidad subjetiva y social de "atreverse a pensar por sí mismo".

Es posible pensar que la figura del maestro ignorante que nos propone Rancière sea un ensayo sobre la autoridad paterna pensada en estos términos, no tanto como el padre real que emancipa al hijo en el hogar, sino como el lugar donde se encarna una ley fundamental, humanizante, creadora de un lazo indispensable para la vida subjetiva, una metáfora.

Esta ley puede encarnarse en un padre, madre o maestro emancipados, autoridades emancipadas, funciones garantes de estos procesos emancipatorios, las transmisoras de emancipación a las generaciones siguientes.

Los desarrollos psicoanalíticos sobre la función paterna nos proveen a su vez, algunas claves para profundizar este tema, aún cuando Rancière no los haya tenido en cuenta como referentes teóricos para su texto. A nuestro entender, los desarrollos de Pierre Legendre (1989), que ponen en diálogo la constitución subjetiva y las categorías institucionales, habilitan esta afirmación. Un padre se instituye en el momento en que deja su lugar de hijo al hijo y se ubica como padre, es decir, ejerce un oficio de mediador con la Referencia, con la Ley en tanto instancia que instituye al sujeto como sujeto de la palabra. En este sentido, Legendre diferencia claramente el lugar de la 
Referencia, del Padre mítico del lugar del padre concreto y ubica a éste como mediador entre el hijo y ese Padre mítico que es principio de Ley y de Razón.

En un lenguaje diferente al de la filosofía política, el del psicoanálisis, Legendre nos ubica, en semejanza con Jacotot y Rancière, en el lugar de esta función paterna que, lejos de adjudicarse el título de propiedad del saber y del poder, garantiza una mediación con la ley fundamental -la de la humanización, emancipación, subjetivación - lejos de demandarlo todo y seguir ubicado en un lugar de hijo ante el propio hijo y en su propio trabajo mediante una actitud dependiente, se emancipa a sí mismo y en ese acto, abre la posibilidad de emancipación del hijo.

Tal vez ningún ámbito, ni el familiar ni el institucional, garantice por sí mismo el funcionamiento de este lugar tercero, menos aún en nuestros tiempos que en los de Jacotot; tal vez hablar de padres, madres o maestros ignorantes emancipados-emancipadores, dadores de un lugar a sus hijos-alumnos, no dueños del saber y del poder, sea un modo de encarnar en una figura visible esta función de autoridad y referencia indispensable para la vida humana.

\section{Conclusión para volver a abrir}

Recorrimos los caminos de la constitución de la subjetividad preguntándonos por los sujetos y sus identidades. Supimos de la identidad que sólo es tal desde otro, retomando los lenguajes de diversas perspectivas teóricas (los enfoques situacionales, el psicoanálisis, la filosofía política). El lazo social, la situación, el proyecto identificatorio, la prestación de identidad y la deuda de vida que es deuda debida, la ley simbólica y la palabra que nombra al sujeto que la busca mientras la hace propia, nos hablaron -en lenguas diversas- acerca de los sinuosos caminos de la emancipación en los que los seres humanos nos hacemos a nosotros mismos con otros, a partir de otros, desde otros, unidos y separados de los otros.

El trabajo en ese espacio intermedio entre-sujetos, sea en la educación o en la crianza de las nuevas generaciones, nos demanda una y otra vez reavivar las preguntas, no tanto por quiénes son ellos y ellas: "los nuevos", 
sino por nosotros mismos en relación a estos "recién llegados" (Arendt, 1958/2005), por nuestros lugares de padres, madres, maestros, autoridades, postas parentales, pasadores de cultura, referentes, anfitriones... y obliga a reformular la tarea irrenunciable e inquietante de la transmisión en tanto productora de subjetividad.

Greco, M. B. (2006). Identities and situations: considerations about emancipation. Psicologia USP, 17 (1), 125-154.

\begin{abstract}
In this work, we crossed the ways of the subjectivity's constitution asking us for the subjects and their identities. We propose that the identity is only in a relationship with another, retaking the theoretical perspectives from differents languages (the approaches about situations, the psychoanalysis, the political philosophy). The social bow, the situation, the identity project, the debt of life, the symbolic law and the words that name the subject, are concepts that speak, in differents ways, about the processes of emancipation in which the human beings become what they are, witth others, from others, next or separated from others. The "ignorant teacher", descripted by Jacques Rancière, is an interesting way to think a different form of emancipation in a relationship with another.
\end{abstract}

Index terms: Identity. Symbolic interactionism. Social influences. Education.

Greco, M. B. (2006). Identités et situations: reflexions sur l'émancipation. Psicologia USP, 17 (1), 125-154.

Résumé: Le texte parcourt les chemins de la constitution de la subjectivité tout en problématisant les concepts de sujet et d'identité. On propose penser que l'identité peut être definie à partir d'un autre, en reprenant différents perspectives théoriques: les perspectives de la situation, la psychanalyse, la philosophie politique. Les concepts de lien social, situation, projet identificateur, prestation d'identité et dette de vie, dette qu'on doit ${ }^{4}$, loi symbolique et parole qui donne un nom au sujet tout en s'appropiant d'elle,

4 en espagnol c'est un jeu de mots qui se prononce de la même façon: deuda de vida et deuda debida. 


\title{
Acerca das Identidades e Situações. Pensamentos sobre a Emancipação
}

\begin{abstract}
parlent - dans des langues différentes- de l'émancipation et ses chemins, où les êtres humains, nous nous faisons à nous mêmes avec des autres, liés et separés des autres. Le travail entre sujets, dans les institutions où la transmission se déploie, nous demande faire à nouveau circuler les questions, pas tellement pour savoir qui sont les "nouveaux venus" mais pour connaître cette place que les adultes occupent en rélation avec les "nouveaux", des lieux de pères, mères, maîtres, autorités, postes, ceux qui passent la culture, ceux qui acueillent... et oblige à penser autrement la tâche irrévocable de la transmission. Finalement, ce texte propose penser les processus émancipatoires et son lien avec la transmission à partir de la figure du maître ignorant, celle de Ranciére, celle qui ouvre à la reflexión sur le lieu de l'autorité éducative et la loi symbolique.
\end{abstract}

Mots clés: Identité. Interaction symbolique. Influences sociales. Education

\section{Referencias}

Arendt, H. (1998). Los orígenes del totalitarismo (G. Solana, trad.). Madrid: Taurus. (Trabajo original publicado en 1951. Título original: The origins of totalitarianism)

Arendt, H. (2005). La condición humana (R. G. Novales, trad.). Buenos Aires: Paidos. (Trabajo original publicado en 1958. Título original: The human condition)

Aulagnier, P. (1988). La violencia de la interpretación. Del pictograma al enunciado. (V. Fischman, trad.). Buenos Aires: Amorrortu. (Trabajo original publicado en 1975. Título original: La violence de l'interprétation. Du pictogramme à l'énoncé)

Baquero, R. (2000). Lo habitual del fracaso o el fracaso de lo habitual. In N. Boggino \& F. Avendaño (Comp.), La escuela por dentro y el aprendizaje escolar (pp. 11-24). Rosario: Homo Sapiens.

Baquero, R. (2002). Del experimento escolar a la experiencia educativa. La "transmisión" educativa desde una perspectiva psicológica situacional. Perfiles Educativos, Tercera Epoca, 24(97-98), 5775.

Burman, E. (2000). La deconstrucción de la psicología evolutiva. Madrid: Visor. (Trabajo original publicado en 1994. Título original: Deconstructing developmental psychology)

Freud, S. (1973). Introducción al narcisismo. In S. Freud, Obras completas (L. LopezBallesteros y de Torres, trad., 3a ed., Vol. 2, pp. 2017-2033). Madrid: Biblioteca Nueva. (Trabalho original publicado em 1914) 


\section{Maria Beatriz Greco}

Frigerio, G. (2003). Alteridad es el otro nombre de la identidad. In G. Frigerio \& G. Dicker (Coord.), Una ética en el trabajo con niños y jóvenes. La habilitación de la oportunidad (pp. 142-154). Buenos Aires: Noveduc-Cem.

Foucault, M. (1994). Qu'est-ce que Les Lumières? In M. Foucault, Dits et écrits (Tomo 4 - 1980-1988, pp. 562-578, bajo la direction de D. Defert \& F. Ewald con la colaboración de J. Lagrange). Paris: Gallimard.

Gauny, G. (1983). Le philosophe plébéien (Textos presentados et reunidos por J. Ranciére). Paris: La Découverte/Maspero.

Hassoun, J. (1994). Les contrebandiers de la mémoire. Paris: Syros.

Jacotot, J. (1829). Enseignement Universe. Langue maternelle. Paris: Bureau du journal de l'emancipation intellectuelle.

Jabés, E. (1991). El libro de las preguntas (J. M. Arancibia, trad., Vol. 2) Madrid: Siruela. (Trabajo original publicado en 1967. Título original: Le livre des questions)

Kant, I. (1784). Was ist Aufklärung. In Berlinische Monatschrift, 4, 481-491.

Kammerer, P. (2000). Adolescents dans la violence. Paris: Gallimard.

Legendre, P. (1989). Leçons VIII: le crime du caporal Lortie. Traité sur le père. Paris: Fayard

Lyotard, J. F. (1990). Mainmise. Autres Temps. 25,16-26.

Navet, G. (2002). L'émancipation. Paris: L'Harmattan.

Rancière, J. (1981). La nuit des prolétaires. Paris: Fayard.

Ranciere, J. (1985). Savoirs hérétiques et émancipation du pauvre. In Les sauvages dans la cité. Auto-émancipation du people et instruction des prolétaires au xix siècle (pp. 34-53). Paris: Champ Vallon.

Rancière, J. (1987). Le maître ignorant. Cinq leçons sur l'émancipation intellectuelle. Paris: Fayard

Vico, G. (2001). Science nouvelle (A. Pons, trad.). Paris: Fayard. 